\title{
Patterns of Use and Short-Term Outcomes of Minimally Invasive Surgery for Malignant Pheochromocytoma: A Population-Level Study
}

\author{
Chandan Kumar Jha ${ }^{1} \cdot$ Anjali Mishra ${ }^{1}$
}

Published online: 16 December 2015

(C) Société Internationale de Chirurgie 2015

We read with interest the article entitled 'Patterns of Use and Short-Term Outcomes of Minimally Invasive Surgery for Malignant Pheochromocytoma: A Population-Level Study' [1]. Congratulations to the authors for reporting the largest cohort of the patients having this rare disease. They have done a commendable job, considering that it was an analysis of a database and that data were collected over a long period of time. Having said this, we would like to make few comments and have some of our queries answered:

1. As we know, in case of pheochromocytoma, only the presence of metastases (distant or loco-regional lymph nodes) is widely accepted as a predictor of malignancy [2]. Does the database mention how the diagnosis of malignancy was arrived at, especially preoperatively (51.3\% patients were preoperatively diagnosed to have malignant disease [1])?

2. In rest of the cases was malignancy diagnosed solely on the basis of histopathology or was metastasis found during the follow-up?

3. In how many cases were distant metastases found and what were the sites of metastases?

4. The range of tumor size mentioned in Table 1 is 2-300 $\mathrm{mm}$ [1]. How were tumors as small as $2 \mathrm{~mm}$ in size localized? Is it just an error while recording the data or a printing error?

5. In how many cases was the diagnosis of malignancy known before the patient underwent MIS and what were the outcomes (partial adrenalectomy/total adrenalectomy/conversion to open technique)?

6. $38.9 \%$ patients in the minimally invasive surgery group (Table 2) [1] had partial adrenalectomies. Were these patients preoperatively planned to undergo palliative/debulking surgery or it was done because of technical reasons?

\section{References}

1. Goffredo P, Adam MA, Thomas SM, Scheri RP, Sosa JA, Roman SA (2015) Patterns of use and short-term outcomes of minimally invasive surgery for malignant pheochromocytoma: a populationlevel study. World J Surg 39(8):1966-1973. doi:10.1007/s00268015-3040-6

2. Scholz T, Schulz C, Klose S, Lehnert H (2007) Diagnostic management of benign and malignant pheochromocytoma. Exp Clin Endocrinol Diabetes 115:155-159
Chandan Kumar Jha

cjhadmch@gmail.com

1 Department of Endocrine Surgery, Sanjay Gandhi Postgraduate Institute of Medical Sciences, Lucknow, India 